\title{
The Trend of Crimes Committed by Lao Immigrants in Thailand After the Inauguration of ASEAN Community
}

\author{
Jomdet Trimek $^{1}$ \\ ${ }^{1}$ College of Social Innovation, Rangsit University, Pathum Thani, Thailand \\ Correspondence: Jomdet Trimek, College of Social Innovation, Rangsit University, Pathum Thani, Thailand. Tel: \\ 66-86-989-4460. E-mail: jomdet.t@ rsu.ac.th
}

\author{
Received: July 31, $2020 \quad$ Accepted: October 20, $2020 \quad$ Online Published: October 31, 2020 \\ doi:10.5539/ass.v16n11p17 URL: https://doi.org/10.5539/ass.v16n11p17
}

\begin{abstract}
This research is directly relevant to the ASEAN Political - Security Community (APSC). One of the fundamental visions is particularly associated with combatting transnational crime and international challenges effectively in a timely manner. This study has three objectives as follows; (1) to explore causes and current situation of crime resulting from cross-border migration from Laos to Thailand due to the establishment of ASEAN community, (2) to deeply analyse immigration and crime trends across Thai-Lao borders, and (3) to propose approaches to preventing the immigration from Laos to Thailand for criminal purposes. In-depth interviews were conducted to gather crucial information from key informants, followed by two focus group discussions. However, the trend of crimes committed by Lao immigrants in Thailand after the inauguration of ASEAN community is inconsistent with the hypothesis and public fear of general people who believed that checkpoints for border trade for commodity flows and labour transfers would worsen the issues of drugs and illegal immigration. Research findings indicate that drug-related crime and illegal immigration issues tend to decrease because the opening of ASEAN community allows the Thai and Lao governments to strengthen their international relations. It can be stated that warm diplomatic relations between countries are the main factor contributing to successful prevention for transnational crime.
\end{abstract}

Keywords: crime, Thailand, Lao, ASEAN Community

\section{Introduction}

At present, the trend of transnational crime in ASEAN member countries is mostly involved in drug smuggling, sex trafficking, human trafficking of Rohingyas, terrorism, online and telecommunication frauds, and so forth. The flow of criminal cases moves from the country where law enforcement is rigid to the country with weaker law enforcement or the country where criminals can exploit more benefits or better resources. Additionally, the countries that share borders, such as Thai-Lao, Lao-Cambodian, and Lao-Myanmar borders, tend to have drug-related crime issues across the borders. To illustrate, ethnic minorities benefit from drug production and smuggling across Thai-Lao borders to raise funds for fighting with the official government. Then, drugs are spread throughout Thailand and other neighbour countries (Uthayo \& Sathavorn, 2016).

Therefore, it is essential that the Association of Southeast Asian Nations or ASEAN should conduct a trend analysis for crime resulting from migration in the short, medium, and long terms. Also, international political environment that has rapidly changed can bring about both opportunities and challenges to member countries, such as opportunities for enhancing political and security cooperation in the region, or challenges in novel threats, namely transnational terrorism and organised crime. The analysis includes the prevention of immigration for committing crime, operations against transnational criminal organisations, and practices for immigrants, and illegal immigration prevention. Data from this research would be analysed to propose recommendations and guidance for the development of crime prevention strategies in response to the cabinet resolution on 24 January 2017. Furthermore, research results would be utilised for law amendment and relevant national strategies to effectively improve the law and criminal justice system and comply with the purposes of ASEAN community. In addition, Thailand has a long border shared with Laos, and may have problems with different bureaucratic systems between the two countries. As a result, the issues related to illegal migrant labour and crime have particularly existed. According to the above-mentioned importance of issues, Trend Analysis of the Impact of Crime Committed by Lao Migrants in Thailand According to the Establishment of ASEAN Community, 
therefore, aims to study about Lao perpetrators who migrate to Thailand to commit three major crimes, including drug-related crime, illegal immigration, and forgery.

\section{Method}

In-depth interviews were conducted with key informants, recruited by purposive sampling. The recruitment criteria included the selection of participants who work as executives or staff in organisations related to foreigners so that the researcher could acknowledge problems in Thailand emerging from the foundation of ASEAN community.

\subsection{In-Depth Interviews with Key Informants}

Key informants from Lao People's Democratic Republic (Lao PDR) included 1) Mr. Suwit Mangkala, Minister Counsellor, Royal Thai Embassy Vientiane, Lao PDR, and 2) Colonel Somchai Kolatee, Defence Attaché, Royal Thai Embassy Vientiane, Lao PDR.

\subsection{Focus Group Discussions}

The first focus group discussion was held to acknowledge problems related to law enforcement, human rights and freedom protection, and to share knowledge about the immigration of foreigners for criminal purposes according to the opening of ASEAN community. The participants included more than 50 experts and professionals in the criminal justice system from both domestic and international agencies. Consisting of representatives from Immigration Bureau, Narcotics Suppression Bureau, Office of the Narcotics Control Board, Royal Thai Police, Ministry of Interior, Ministry of Labor, Department of Special Investigation, Department of Corrections, Department of Probation, Department of Juvenile Observation and Protection, Ministry of Justice, Ministry of Social Development and Human Security, and National Commission for Justice Administration Development

The second focus group discussion was held to analyse data collected from interviews and information from relevant criminal justice agencies responsible for illegal immigration, drug-related crime, and forgery. The discussion analysed the trend of immigration for criminal purposes in Thailand due to the opening of ASEAN community in the short term (1-3 years), medium term (3-5 years), and long term (5-10 years). Then, the summary and recommendations were concluded to propose solutions to the problems and devise approaches to crime prevention in the future. The participants included more than 20 experts and professionals in the criminal justice system from both domestic and international agencies.

\subsection{Academic Conference for Law Enforcement Officials}

The conference was held to collect comments and suggestions from relevant agencies responsible for the prevention of immigration for criminal purposes due to the opening of ASEAN community. This conference intended to execute and put research findings into practice. The participants included more than 100 experts and professionals in the criminal justice system from both domestic and international agencies.

\section{Literature review}

In the ASEAN Political - Security Community Blueprint 2025, a transcript of transnational crimes stated that: There are six types of transnational crime in the ASEAN region, including kidnapping and human trafficking, drug trafficking, illegal fishing, small arms smuggling, cyber-crimes, and pirates (ASEAN Secretariat, 2009).

One of the visions of the important ASEAN political and security community is the operation to achieve a community that promotes security that covers all aspects. To develop the capability to deal with the challenge of the new security issues especially transnational and cross-border crime effectively and in a timely manner by establishing a plan to strengthen cooperation in solving and combating transnational crime (Huang, 2019). For instance, terrorism drug trafficking, human trafficking, weapons smuggling, piracy, money laundering, economic crime and cyber-crime including emerging transnational crimes such as wildlife and plant trade smuggling (Department of ASEAN Affairs - Ministry of Foreign Affairs of the Kingdom of Thailand, 2016).

According to the statistics, it was found that when the ASEAN Community officially opened in 2016. The participation rate of foreigners in Thailand is increasing (Information Technology Center Immigration Bureau National Police Agency, 2018). The study of crime issues that have changed after the opening of ASEAN community (Department of Corrections Technology Center, 2017) aims to enlighten readers to understand the situation of crime due to the establishment of ASEAN community. Prior to the opening of ASEAN community, Lao PDR had encountered two main problems, including drug-related issues and illegal immigration to Thailand.

1) Drug-related issues - the production of drugs in Laos exists in three places. The biggest source of drugs is located in Vientiane, where drugs from Myanmar are compressed into tablets. There are nine main drug hiding 
places in Vientiane and Muong Song Khone, Savannakhet, on the opposite side of Mukdahan and Ubon Ratchathani. The areas where drug traffickers travel from Laos to Thailand are along the Thai-Lao borderline. Lao migrant workers who are drug traffickers mostly smuggle addictive substance at night via natural borders and temporary checkpoints. Smuggling is usually involved in concealing drugs in internal organs. For instance, drugs might be bundled into 10-20 double-wrapping condoms. Each bundle can consist of 100-200 pills. Then, those condoms were hidden in an anal or vaginal cavity. Furthermore, drug smugglers can hide drugs in various places and separate themselves to different buses and meet up again at the assembly point to spread drugs in Thailand.

2) Illegal immigration - this has been a long-lasting problem on the Mekong River, which is the natural boundary between Thailand and Laos. This issue has been considered unpreventable and unsolvable, especially in the south of the north-eastern region including Ubon Ratchathani, Amnat Charoen, and Mukdahan. The National Intelligence Agency states that there are more than 200,000 Lao migrant labourers crossing this border each year. Illegal Lao migrant workers are in the age range of 12 to 50 years old, travelling from Attapeu, Sekong, Champasak, and Savannakhet. Most of illegal immigrants cross the border in Ubon Ratchathani. Most illegal migrant workers are in labour trafficking business, owned by both Thai and Lao traffickers. Commission fee that each worker needs to pay is around 3,000 - 5,000 baht. When Lao labourers take the ferry from Laos to Thailand, labour trafficking agents will group them into $5-10$ people to take a car to inner region. Stopping and transferring points are in Ban Dong Nong Luang, Khemmarat District, Ubon Ratchathani, where they can travel through a dirt road which links to Arun Prasert Road, the main road to Bangkok. Lao migrant labourers usually travel to Thailand by single-cab pick-up trucks equipped with roof, which look like vegetable trucks. Moreover, the trucks are mostly covered by truck canvas. Some traffickers may use four-door pick-up trucks or vans to transfer migrant workers. A caravan usually consists of 3 - 7 trucks, including vehicles leading and closing the procession to help notify the others of checkpoints along the journey (Trivej, 2008).

Judicial process in Laos starts from the court of first instance (Vientiane Court), which has power to hear and decide every type of cases or lawsuits, including unlimited civil cases. The law states that the court should render its judgment within two months after a lawsuit is filed. However, public disclosure of the judicial process is not allowed. Only judgments and verdicts are disclosed to the public. Furthermore, some cases cannot be appealed, such as political lawsuits (Office of the Judiciary, 2015). Alternative dispute resolutions in Laos has been amended according to the law on the promotion of foreign investment, which states that when an investment dispute emerges, it should be resolved by domestic or international dispute resolutions. Domestic dispute resolutions are comprised of negotiation, mediation, conciliation, arbitration, and the People's Courts of Laos. Nevertheless, if the dispute is a small claim dispute or low value dispute, namely family disputes and animal custody disputes, it is compulsory that family mediation should conduct a resolution. If family mediation fails, the District Justice Office should conduct a mediation and provide knowledge for people involved (Office of the Judiciary, 2015). In case a foreigner is arrested in Laos, the case must be directly reported to the embassy. However, detention visitation is rarely permitted due to Lao specific laws, except the case that the detainee is sent to the penitentiary or court of justice. The Royal Thai Consulate-General is responsible for taking care of the detainee.

In terms of cooperation in extradition, Thailand has a mutual legal assistance treaty with other nations. There are laws giving legal power for extradition, such as the Extradition Act, B.E. 2472 (1929) and the Extradition Act, B.E. 2551 (2008). Extradition is a matter involved in international relations and sovereignties of each nation. Although there is a mutual legal assistance treaty on extradition between Thailand and Laos, Thailand still has difficulties in international cooperation in extradition in practice. Previously, Thailand has no contracts with Laos; therefore, a request for extradition needs to be performed in form of a reciprocal contract. When Laos requests for a criminal committing a crime in its jurisdiction and escaping to Thailand, Thailand will help arrest him and extradite him back to Laos (Sook-rom, 2018).

\section{Results}

Research findings can be categorised into 3 parts, including 1) trend analysis of crime committed by immigrants in Thailand, 2) approaches to crime prevention, and 3) recommendations. These can be described in more details below.

\subsection{Trend Analysis of Crime Committed by Immigrants in Thailand}

\subsubsection{Drug-Related Cases}

Laos is merely a transit country where drug traffickers smuggle illicit substances to Thailand. It was not until recently that Laos had problems with drug trafficking. As other drug trafficking routes have been strictly 
patrolled, Laos has become a new route for drug smuggling to Thailand.

1) Trend Analysis in the Short-Term (1 - 3 Years)

The number of Lao perpetrators convicted of drug-related crime will be significantly decreasing after the opening of ASEAN community. Laos is a transit country for drug trafficking to Thailand. As the opening of ASEAN community has strengthened the relationship between Thailand and Laos, law enforcement agencies in the two countries will cooperate and share information with each other. Therefore, the integration of agencies between countries can better prevent and deter drug trafficking, resulting in difficulties in drug smuggling to Thailand. Consequently, the number of arrested criminals will be reducing.

2) Trend Analysis in the Medium-Term (3 - 5 Years)

The trend of the impact of drug-related crime committed by Lao migrants in Thailand in the next $3-5$ years will be decreasing constantly. This is because the integration of law enforcement agencies between Thailand and Laos is more effective. Law enforcement agencies can better understand each other's work culture and share much more information about drug trafficking. Therefore, narcotics prevention and suppression will be more effective. Consequently, the number of criminals convicted of drug-related crime in Thailand will be reducing.

3) Trend Analysis in the Long-Term (5 - 10 Years)

The trend of the impact of drug-related crime committed by Lao migrants in Thailand in the next $5-10$ years will be dramatically decreasing. The cooperation and integration of all law enforcement agencies in Thailand and Laos can enhance the efficiency of drug prevention and suppression. Regular border patrols for drug smuggling activities will be more effective. Consequently, the number of criminals convicted of drug-related crime in Thailand will be significantly reducing.

\subsubsection{Illegal Immigration Cases}

After the inauguration of ASEAN community, the Thai and Lao governments have agreed to collaborate on reducing illegal immigration issues. The Government of Lao PDR signed a memorandum of understanding on employment cooperation with the Royal Thai Government on 6 July 2016, resulting in the same repercussion as Myanmar labourers. To illustrate, the number of perpetrators convicted of being employers who employ alien workers without a work permit had decreased from 40 in 2015 to 3 in 2016, and 1 in 2017. Likewise, the number of illegal immigrants had doubled from 19,531 in 2015 to 38,641 in 2016, and 26,056 in 2017 (Offences related to the Immigration Act B.E. 2522 (1979) for illegal Lao immigrants from 2008 to 2017).

\section{1) Trend Analysis in the Short-Term (1 - 3 Years)}

The number of illegal Lao immigrants will be decreasing particularly after the opening of ASEAN community. As the Thai and Lao governments have an agreement to collaborate on employment, illegal foreign workers in Thailand have become legitimate. However, the number of illegal Lao immigrants will still be remained in the next $1-3$ years because they may not have seen the benefits of lawful foreign workers registration yet.

2) Trend Analysis in the Medium-Term (3 - 5 Years)

In the next $3-5$ years, the number of illegal Lao immigrants will be decreasing because they will have better seen the benefits of lawful immigration and foreign workers registration. If the Lao government provides knowledge about immigration to Thailand for the public thoroughly and consistently, the number of illegal immigrants will be reducing. Also, there will be a significant increase in lawful Lao labourers in Thailand.

3) Trend Analysis in the Long-Term (5 - 10 Years)

In the next $5-10$ years, the number of illegal Lao immigrants will be significantly decreasing because they will have seen both advantages and disadvantages of lawful foreign workers registration. As a result, they will wish to work lawfully in Thailand and avoid risking their lives or spending their costs on illegal immigration.

\subsubsection{Forgery Cases}

1) Trend Analysis in the Short-Term (1 - 3 Years)

There will be only a few Lao perpetrators convicted of forgery because the Thai government has a policy to transform illegal labourers into legitimate workers in Thailand. Therefore, the number of Lao criminals committing forgery tends to decrease. Illegal Lao workers who used to forge official documents will become legitimate foreign workers and no longer need forged documents.

2) Trend Analysis in the Medium-Term (3 - 5 Years)

In the next $3-5$ years, the number of Lao perpetrators convicted of forgery will be increasing. As the vast 
majority of Lao workers wish to work in Thailand lawfully for privileges, there will be a rise in criminal cases related to forgery.

\section{3) Trend Analysis in the Long-Term (5 - 10 Years)}

In the long run, if both governments fail to launch a tough policy to reduce forgery issues, forgery will be a major problem that causes difficulties in law enforcement. Modern technologies will allow criminals to perfectly forge official documents, resulting in difficulties in detection especially fake passports. Meanwhile, certain law enforcement officials may not have expertise in detecting forged documents and may subsequently fail to arrest the offenders.

\subsection{Crime Prevention Approaches}

Thailand will need to promote better international relations with the Lao government in order to prevent drug-related issues and illegal immigration at the moment, and forgery issues in the future. Law enforcement agencies in the two countries should also better strengthen their relationship. As Laos is a socialist state where endorses communism, operational frameworks and bureaucratic systems are different from Thailand. Information sharing may be difficult because Laos rarely discloses national data to the public. Therefore, amicable relations between Thailand and Laos as well as their law enforcement agencies are particularly essential when arresting Lao criminals in Thailand. In addition, the Thai government should have an agreement with the embassy of the Lao PDR in Thailand to assign a contact person or responsible agent for extradition when Lao perpetrators are arrested in Thailand.

\subsection{Recommendations}

According to two focus group discussions and in-depth interviews with key informants at the Royal Thai Embassy Vientiane, Lao PDR, recommendations from this research can be proposed to four institutes, including 1) Royal Thai Government, 2) National Commission for Justice Administration Development (NCJAD), 3) Royal Thai Police, and 4) Immigration Bureau and Office of the Narcotics Control Board (ONCB).

\subsubsection{Recommendations for the Royal Thai Government}

1) The government should govern communities at the city level in order to strictly control the areas where Lao migrant workers reside. Particularly, the government should reduce transnational crimes and crimes committed by migrant labourers in society.

2) Law enforcement officials must perform their duties with honour and integrity. Corrupt officials and those with professional misconduct must be appropriately punished to prevent others from corruption.

3) The government should promote international relations with other nations, especially diplomatic relations, in order to build trust and strengthen high-level international relations.

4) The government should emphasise the importance of drug-related issues and transnational crime. It is recommended that the government push forward neighbour countries and Thailand to drive more practical and tangible policies towards the problems.

5) The government should develop international cooperation on transnational crime prevention and suppression in ASEAN by sharing knowledge and information about each nation's specific identity. The understanding between countries will help develop crime prevention measures in each country.

\subsubsection{Recommendations for the National Commission for Justice Administration Development (NCJAD)}

1) The NCJAD should promote international relations between law enforcement and criminal justice agencies in neighbour countries in order to share information and integrate forces to prevent all types of crime.

2) The NCJAD should share knowledge and information about novel and complicated criminal patterns in order to enhance the efficiency of crime prevention in Thailand.

3) The NCJAD should inspect law enforcement officials and encourage them to perform their duties with honour and integrity. Corrupt officials and those with professional misconduct must be obviously punished to prevent others from corruption.

4) The NCJAD should support officials in immediate deportation of illegal immigrants to save budgets and reduce the number of detainees in Thai immigration detention centres and prisons.

\subsubsection{Recommendations for the Royal Thai Police}

1) The Royal Thai Police should inspect relevant police officers to strictly perform their duties to prevent illegal immigration and drug trafficking in Thailand. 
2) The Royal Thai Police should provide trainings for police officers at the operation level to develop police tactics and skills related to the inspection of foreign workers' documents.

3) The Royal Thai Police should collaborate with police agencies in other countries to enable information sharing and inter-agency collaboration for effectively preventing illegal immigration, drug smuggling, and forgery.

4) The Royal Thai Police should encourage the Royal Police Cadet Academy to provide academic scholarships for police cadets in neighbour countries to study in Thailand. Police cadet exchange programmes will efficiently enhance cooperation on police work between Thailand and neighbour countries, resulting in a reduction in crimes committed by immigrants in Thailand.

5) The Royal Thai Police should deploy police attachés to all embassies in neighbour countries, especially in ASEAN to collaborate with each other to better combat transnational crime.

\subsubsection{Recommendations for Immigration Bureau and Office of the Narcotics Control Board (ONCB)}

1) Relevant agencies should urgently control immigration and migrant labourers and make the system and process inspectable.

2) Relevant agencies should devise rigid measures and conditions for immigration. They should also perform frequent border patrols, covering international points of entry between Thailand and neighbour countries especially natural borders. Border patrols can prevent illegal immigration and drug trafficking into Thailand.

3) Relevant agencies should provide trainings for officials at the operational level in order to develop tactics and skills related to the inspection of foreign labourers in Thailand.

4) Relevant agencies should adapt work patterns of inspectors and be responsible for dealing with migrant workers issues more strictly and sophisticatedly.

5) Relevant agencies should update their information to respond to the current situation and potential changes in the future to effectively encounter migrant labour issues in Thailand.

\section{Conclusion}

The opportunities for investment in ASEAN community are a factor leading to crimes committed by Lao immigrants in Thailand. Investments in Thailand and Laos follow the global trends that keep changing due to modern globalization, leading to more convenient commodity flows and labour-transfer process. The changes of modern globalization have an impact on existing problems, which are drug-related crime and illegal immigration. Research findings indicated that there were three main types of crime, including illegal immigration, drug-related crime, and forgery. However, after the establishment of ASEAN community, police and army from both Thailand and Laos have better strengthened their relationship and capacity to integrate forces, share information, and contact each other to arrest perpetrators. Therefore, the ASEAN community is an important factor that helps mitigate the impact of crime originating from the immigration of Lao people to Thailand.

\section{References}

ASEAN Secretariat. (2009). ASEAN Intergovernmental Commission on Human Rights. Retrieved from https://www.asean.org/storage/images/archive/publications/TOR-of-AICHR.pdf

Department of ASEAN Affairs - Ministry of Foreign Affairs of the Kingdom of Thailand. (2016). ASEAN 2025: Forging ahead together. Department of ASEAN Affairs, Ministry of Foreign Affairs of the Kingdom of Thailand, Bangkok, Thailand.

Department of Corrections Technology Center. (2017). Report of the prisoners statistics. Retrieved from http://www.correct.go.th/stathomepage/

Huang, K. B. (2019). The Origins of the ASEAN Community's Humanitarian Component. Chinese Journal of International Review, 1(1), 1-21. https://doi.org/10.1142/S263053131950001X

Information Technology Center Immigration Bureau National Police Agency. (2018). Statistics of Foreigners in and Out of Travel. Retrieved from https://www.immigration.go.th/immigration_stats

Office of the Judiciary. (2015). Knowledge of Legal and Judicial Systems in ASEAN Countries. Bangkok: Foreign Affairs Division, Office of the Judiciary.

Sook-rom, K. (2018). Extradition: Methods to extradition to Thailand for Prosecution or Punishment. Retrieved from http://fad.go.th/th/articles/108431

Trivej, S. (2008). Migrant Workers and Drug Trafficking in Thailand. Judicial Training Institute, Office of the 
Judiciary, Bangkok, Thailand.

Uthayo, P., \& Sathavorn, P. (2016). ASEAN 2025: Forging Ahead Together to Combat Crime. Journal of Criminology and Forensic Science, 2(1),

https://so02.tci-thaijo.org/index.php/forensic/article/view/185361

\section{Copyrights}

Copyright for this article is retained by the author(s), with first publication rights granted to the journal.

This is an open-access article distributed under the terms and conditions of the Creative Commons Attribution license (http://creativecommons.org/licenses/by/4.0/). 